\title{
Analysis of Thermal Behavior of Materials in the Building Envelope Using Building Information Modeling (BIM) -A Case Study Approach
}

\author{
Maryam Habibi Anbouhi, Nariman Farahza, Seyed Mohammad Hossein Ayatollahi \\ Department of Art and Architecture, Yazd University, Yazd, Iran \\ Email: maryamhabibi27@yahoo.com,n_farahza@yazd.ac.ir, hayatollahi@gmail.com
}

Received 4 August 2016; accepted 11 September 2016; published 14 September 2016

Copyright (C) 2016 by authors and Scientific Research Publishing Inc.

This work is licensed under the Creative Commons Attribution International License (CC BY). http://creativecommons.org/licenses/by/4.0/

(c) (i) Open Access

\begin{abstract}
Building envelope is a fence that controls heat exchange between interior and exterior and plays an essential role in providing thermal comfort conditions of residents. In recent years, due to the necessity of conserving energy and also preventing increased environmental pollution, the importance of sustainable construction has been doubled. Checking the problems of thermal behavior of the building envelope materials, and what influences in the heating and cooling loads exerted and energy consumption of buildings, are the questions that this research seeks to answer. In this regard, building information modelling analysis (BIM) has worthy contribution in the completion process of sustainable design; thus using software Design Builder, it is paid attention to simulation of the thermal behavior of two types of defined materials for the building envelope that was designed as a Research Institute of Renewable Energy of Yazd University ${ }^{1}$. For Type 1 materials, two layers of brick have been selected, and for Type 2 a thermal insulation layer also added it. Results of the analysis showed that the use of materials Type 2 in the cooling load $4.8 \%$ and in the thermal load $62.5 \%$ reduction can be achieved which means reducing the load on active system and thus reducing the initial cost of building. Also reduction in annual energy consumption by almost $\mathbf{2 . 4 \%}$ for cooling and $\mathbf{6 2 . 9 \%}$ for heating buildings have been achieved, which makes saving non-renewable energy consumption, and consequently reducing environmental pollution as well as reducing current costs will be established.
\end{abstract}

\section{Keywords}

Building Envelope, Sustainable Design, Building Information Modelling (BIM), Thermal Comfort,

\footnotetext{
${ }^{1}$ This article is adapted from the author's MA thesis, entitled: "Design for Research Center of Renewable Energy in Yazd” that has been conducted by the second author's guidance and third author’s advice in March 2016, Yazd University. 


\section{Thermal Insolation}

\section{Introduction}

According to data published by Iran's electric power industry statistics, about $40 \%$ of total energy consumption accounted for buildings that this important issue indicates the need to saving energy in Iran [1]. However there is less research that has been done in Iran, so the design is carried out in the Yazd city, which is one of the historic towns located in the central plateau of Iran, and has warm and dry weather. Since in these areas there is simultaneous need to provide heating and cooling in buildings in hot and cold seasons, the necessity of saving in both sectors is more reflected, so in order to find appropriate solutions to save energy consumption, thermal behavior modification of building envelope could be a useful strategy.

Building envelope as a main interface between the interior and exterior plays a significant role in moderating climate conditions and provides comfort of the residents. Thus reduction of heating and cooling loads, and implementation of building envelope that could provide highest thermal comfort in the interior with the lowest use of mechanical equipment by good thermal behavior, could cause largely saving in energy consumption. In vernacular architecture hot and dry regions of Iran, thick walls with high thermal mass could largely be outside ambient temperature conditions modulators and supplier of comfort conditions for building residents. In this architecture, thatch, clay and bricks to build walls up to $60 \mathrm{~cm}$ in diameter were used. The spread of beam and column system rather than load-bearing wall system, expensive land prices and high buildings, were accounted for ability and desire to reduce the thickness of the walls as much as possible [2]. As a result, due to the small wall thickness it should use the materials that saving energy consumption should be followed.

This research using building information modelling (BIM) in Design Builder software deals with analyzing the thermal behavior of two types of materials. The first one is a two-layer brick wall which is common in making walls in Yazd city, in particular on project design, and the type 2 by adding a thermal insulation layer between two layers of brick has been considered. In this research, in addition to taking into account energy consumption in both types, the effects of thermal mass wall heating and cooling loads of the building have been measured.

\section{Methodology}

At first, to gather the necessary information to complete the theoretical framework of research library studies, papers, magazines and valid global information database have been utilized. In the next step in order to apply previous studies in line with scrutinized issue it was paid to similar examples. Finally to test the accuracy of the findings quantitatively, building information was modelled in Energy audits Software Design Builder. At first analyses have been done as assessment of heating and cooling loads to buildings in the coldest and warmest days of the year to separate the two types of materials proposed to determine the amount of savings in initial costs of building to meet heating and cooling equipment using materials type 2. Finally, by analysis the annual energy consumption in the building the savings in energy consumption to provide comfort conditions within the design by type 2 materials were determined.

\section{Sustainable Design}

One of the most common definition of sustainability, according to the 1987 United Nations Commission Bratland presented; "Sustainability means meeting the needs of the present generation without compromising the ability of future generations to meet own needs" [3]. There is a common interpretation of sustainable development in the construction industry; to provide building using less energy and materials, and producing less pollution and waste in the environment [4] [5]. Sustainable building construction not only matches to climatic conditions in its area, but also establishes mutual relationship. Moreover increasing energy efficiency during the lifetime of building is the most important goal of sustainable design [6], this approach can also help industrialization of construction activities [7].

There are many ways to describe the sustainable design including reducing consumption, reuse, recovery and recycle of resources and materials [8], this research is focused on "reduction" energy consumption. Although the term reduction could create an image of loss, however, in principle, it implies on reducing waste and excessive 
consumption of resources and materials in the construction industry.

\section{Sustainable Design and BIM}

Today experts have more emphasized on BIM and suitable design strategies since the importance of BIM has become increasingly understood [9]. Energy usage analysis has been the subject of a number of published papers on BIM related sustainable design [10]-[13].

Building Information Modeling (BIM) is defined as a digital representation of the building process to facilitate exchange and interoperability of information in digital format [7]. A complete set of design documents stored in an integrated database and information about the entire building are employed in BIM. This information is totally parametric and as a result interconnected. In all views any changes to an object within the model and immediately reflected throughout the rest of the project. Despite a two-dimensional representation of the building which is commonly found in CAD-based drawings a BIM model includes the buildings actual assemblies and constructions and as a result a 3-D virtual environment with a workflow of integrated information through a software package will be obtained [14] [15]. Improved design and building performance will be enabled in Building Information Modeling (BIM) which is ideally suited to the delivery of information. Integration Project Delivery (IPD) and Design Optimization are two major beneficial features of BIM with respect to sustainable building design. However, designers will be able to optimize the building design more efficiently in the very early stages of the entire process and achieve a better solution using BIM [16].

There are numerous applications in the field of Building Information Modelling (BIM) which one of them is Energy audits software, Design Builder. Thus, to study and analysis of this issue that the structures intended for exterior walls, according to previous studies, to what extent can work in Yazd climate, and also to assess their impact on saving energy and initial and ongoing costs of building, the software has been utilized. This tool is designed to simulate and analysis climatic spaces, and energy plus engine in the software has been assessed invalid tests, and also in many valid scientific articles have been used as criterion of measurement [17]. The validation results of the software are available on the website of Energy Plus. Simulation and Design in Design Builder is used using the thermal equilibrium of heating and cooling load based on the ASHRAE standard. In this study, the 4.5.0.148 version of this for building information simulation has been used.

\section{Building Envelope}

Building envelope is a fence that controls heat exchange between interior and exterior, and plays an important role in providing thermal comfort conditions of residents. The ability to control and modify the permeability of building envelope gives the ability to the building that to be able to react to changes in local weather conditions. It means that the exterior walls should act as a filter responsive to local climate [18]. Building envelope is exposed to variable temperature during the day. In other words, in addition to insulation against heat, useful thermal mass of wall which is a function of heat capacity, density and thermal conductivity of its constituent layers also plays an important role in the functioning of the wall [19]. It is also noteworthy that the thermal mass, which is more effective when the range of outside temperature changes in a 24-hour cycle is high (about 10 hours) [20]. Therefore, thermal mass effect has the greatest advantage in hot and dry climate during the summer [8]. In general, thermal materials that have useful features, either are heat insulation or thermal mass [20]. So the influence of these two features, i.e. the thermal mass and thermal insulation, should be considered simultaneously.

\subsection{The Role of Thermal Mass and Thermal Insulation in the Building Envelope}

Materials that have a high thermal mass, when exposed to heat-treated, can hold more heat compared to other materials, also when the heat source is removed, they release the heat stored in its own at a slower rate [21]. Thus, a building can use the thermal mass to reduce heat absorption, by delaying the entry of heat into the building until the sun sets [8].

During the winter, materials with high thermal mass preserve thermal energy from the sun which has been entered through the openings into the interior space and has been locked, and then the evening when the sun sets and the heat source is removed and the more heat is required in the interior space, again this heat is given back to the interior slowly. This led to reduce heating load of building [22]. In summer, it also absorbs thermal mass heat generated by sunlight in the interior spaces gradually, and prevents a sudden increase in temperature and 
pressure at once on cooling device. Then when the materials were stuffed full of warmth, begin to release heat stored in their own; Part of the heat is given back into the interior and the other part is radiated to exterior [23].

In order to time lag, location of thermal mass is not much sensitive. On the external side of Insulation, the mass can create a durable shell and resistant to weather. On the internal side of insulation, the mass can strengthen the cooling through night ventilation in summer and passive solar heating, but in order to achieve all the benefits, it should be divided the mass by an insulation layer [8]. The role of heat insulation, reducing the heat transfer rate is different between spaces with various temperatures that prevents the heat loss through the building envelope in winter and heat transfer into the interior in summer.

\section{Case Studies: Yazd City}

\subsection{Yazd Climate}

Yazd city with an area of 99.5 square kilometers is located in center of Iran, and according to coupon's category the city is in the second class, it means that is located in warm and dry climate. In these regions, because the amount of annual precipitation, does not meet the required steam for humidity, the weather is generally dry. Warm and dry summers and harsh and cool winters are characteristics of this climate [24], which can be seen in Table 1.

\subsection{Thermal Comfort Temperature Yazd City}

Thermal comfort conditions, is the range of temperature and humidity that the mechanism of regulating the body temperature is at least activity [25]. Determination of the range of Thermal comfort has direct influence in building thermal calculations, the size of heating and cooling devices and materials, and generally consumption and energy Losses. People in the same climatic conditions feel similar thermal comfort [26], so it is necessary the thermal comfort range be determined accurately for each climatic. There are few studies in this field for Yazd climate in which one example of available calculations in addition to review and compare thermal comfort region, the Olegy method has been used in which matching capability for the latitudes below 40 degrees has been predicted, Comfort temperature was also calculated for Yazd city [27].

To determine thermal comfort regions in Yazd, it is necessary to proposed that the above-mentioned range with respect the thermal conditions in summer and winter. Hence by calculating average relative humidity monthly and annual, and average dry bulb temperature of Yazd station monthly and annual during the period of 10 years (1997-2006), determination of monthly and annual the position of the mentioned stations on the Olegybioclimatic chart, upper and lower limit of thermal comfort was obtained, and it can be said that thermal comfort range for summer in Yazd city is $21 / 8^{\circ} \mathrm{C}-27^{\circ} \mathrm{C}$ and thermal comfort range for winter is $20 / 4^{\circ} \mathrm{C}-23^{\circ} \mathrm{C}$ [27] [28]. According to this model, to determine the limits of thermal comfort in addition to temperature, the relative humidity of the air should be determined. According to the minimum and maximum relative humidity in the city of Yazd in January and June, 53\% - 18\% has been considered.

\subsection{Selection of Building Materials}

Given the interviews with experts in the construction industry and field observations written by the designed site (site of Yazd University), building common materials that are used for exterior walls in Yazd city are mainly brick. Due to the high thermal capacity, it creates a thermal mass in outer wall and also is considered a part of local materials, thus is intended for type 1 and by adding a thermal insulation layer to it, it has been tried to correct its thermal behavior in the heating and cooling load exerted on the building. In Table 2, two types of materials used in two types of simulated external walls has been shown separately.

\section{Building Information Modelling in Software Design Builder}

As mentioned in Section 4; in this study to simulate building information modelling with the following proper-

Table 1. Weather characteristics of Yazd city www.moe.gov.ir.

\begin{tabular}{|c|c|c|c|c|c|c|c|}
\hline City & $\begin{array}{l}\text { Sea Level } \\
\text { (m) }\end{array}$ & Latitude & $\begin{array}{l}\text { Minimum dry winter } \\
\text { temperature }\left({ }^{\circ} \mathrm{C}\right)\end{array}$ & $\begin{array}{l}\text { Maximum wet summer } \\
\text { temperature }\left({ }^{\circ} \mathrm{C}\right)\end{array}$ & $\begin{array}{c}\text { Maximum dry summer } \\
\text { temperature }\left({ }^{\circ} \mathrm{C}\right)\end{array}$ & $\begin{array}{l}\text { Air Pressure } \\
(\mathrm{KPa})\end{array}$ & $\begin{array}{l}\text { Dew Point } \\
\left({ }^{\circ} \mathrm{C}\right)\end{array}$ \\
\hline Yazd & $1219 / 2$ & $31 / 88$ & $40 / 00$ & $18 / 33$ & $-5 / 28$ & $87 / 56$ & $5 / 36$ \\
\hline
\end{tabular}


Table 2. External walls types www.moe.gov.ir.

\begin{tabular}{lcccc}
\hline External Wall & & & & \\
\hline External Wall (Type 1) & $\mathrm{K}\left(\mathrm{w} /{ }^{\circ} \mathrm{k}\right)$ & Thickness $(\mathrm{m})$ & Density $\left(\mathrm{kg} / \mathrm{m}^{3}\right)$ & Specific heat $\left(\mathrm{j} / \mathrm{kg}\right.$ - $\left.^{\circ} \mathrm{k}\right)$ \\
\hline 1. Brick & 1.16 & 0.1 & 1920 & 840 \\
2. Sand \& cement mortar & 1.00 & 0.03 & 1700 & 840 \\
3. Brick & 1.16 & 0.2 & 1920 & 840 \\
4. Plaster lining & 1.1 & 0.02 & 1500 & 1000 \\
5. Plaster & 0.4 & 0.01 & 1000 & 1000 \\
\hline External Wall (Type 2) & & & 1920 & 840 \\
1. Brick & 1.16 & 0.03 & 1700 & 840 \\
2. Sand \& cement mortar & 1.00 & 0.02 & 1920 & 840 \\
3. Brick & 1.16 & 0.11 & 175 & 840 \\
4.Termal Insolation & 0.047 & 0.05 & 1920 & 840 \\
5. Brick & 1.16 & 0.11 & 1500 & 1000 \\
6. Plaster lining & 1.1 & 0.02 & 1000 & 1000 \\
7. Plaster & 0.4 & 0.01 & & \\
\hline
\end{tabular}

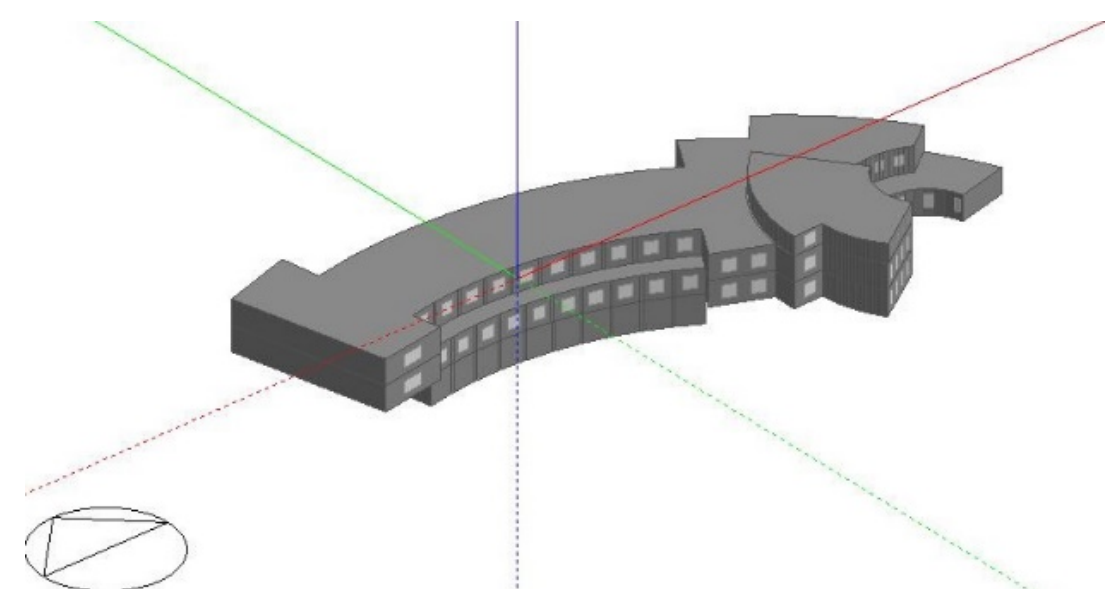

Figure 1. Design builder 3-D model of building (Authors, 2016).

ties, software Design Builder has been utilized which is seen in Figure 1 and also can be seen the building floor plans in Figures 2-4. The lower floor on the basis of its performance and less space requirement to light and natural ventilation, it has been sunk into the ground to reduce building energy losses, and the other two floors are located on the ground which is seen in Figure 4. Building orientation to take advantage of solar energy in winter has been south-facing location, and it has been utilized the opening with an area of $12 \%$ in respect with given area to collect sunlight and also thermal mass of concrete material with a thickness of $12 \mathrm{~cm}$ in the bottom to absorb solar energy in direct absorption system in order to passive heating. To evaluate the effect of the outer envelope on the conditions and temperature comfort, the structural of ceilings and floors and interior walls and also windows in both models has been considered, and only the materials of exterior walls according to Table 2 are variable. The materials of windows are double glazed PVC filled by air, those of floors are piles and blocks that in lower floor has been laid by plaster and in upper floor by granite stone, and the external ceilings have 5 cm thermal insulation of rock wool.

In this simulation information related to residents, Office and laboratory equipment, lighting, air conditioning, since are the heating and cooling load factors imposed on the building, have been considered completely in the software in order to the obtained results to be closer to reality. Yazd climate file also has been chosen from Weather bank related to Software site and has been loaded in software, and also to define thermal comfort range of inside the building the previous studies has been utilized. 


\section{Results and Discussion}

First, to get the peak heating and cooling loads acting on the building, analysis is done in hottest and the coldest days of the year, as we know, the peak load values can be used to select air conditioning equipment. Thus, proving the effect of thermal insulation to reduce energy consumption, and to obtain its rate, the analysis of both

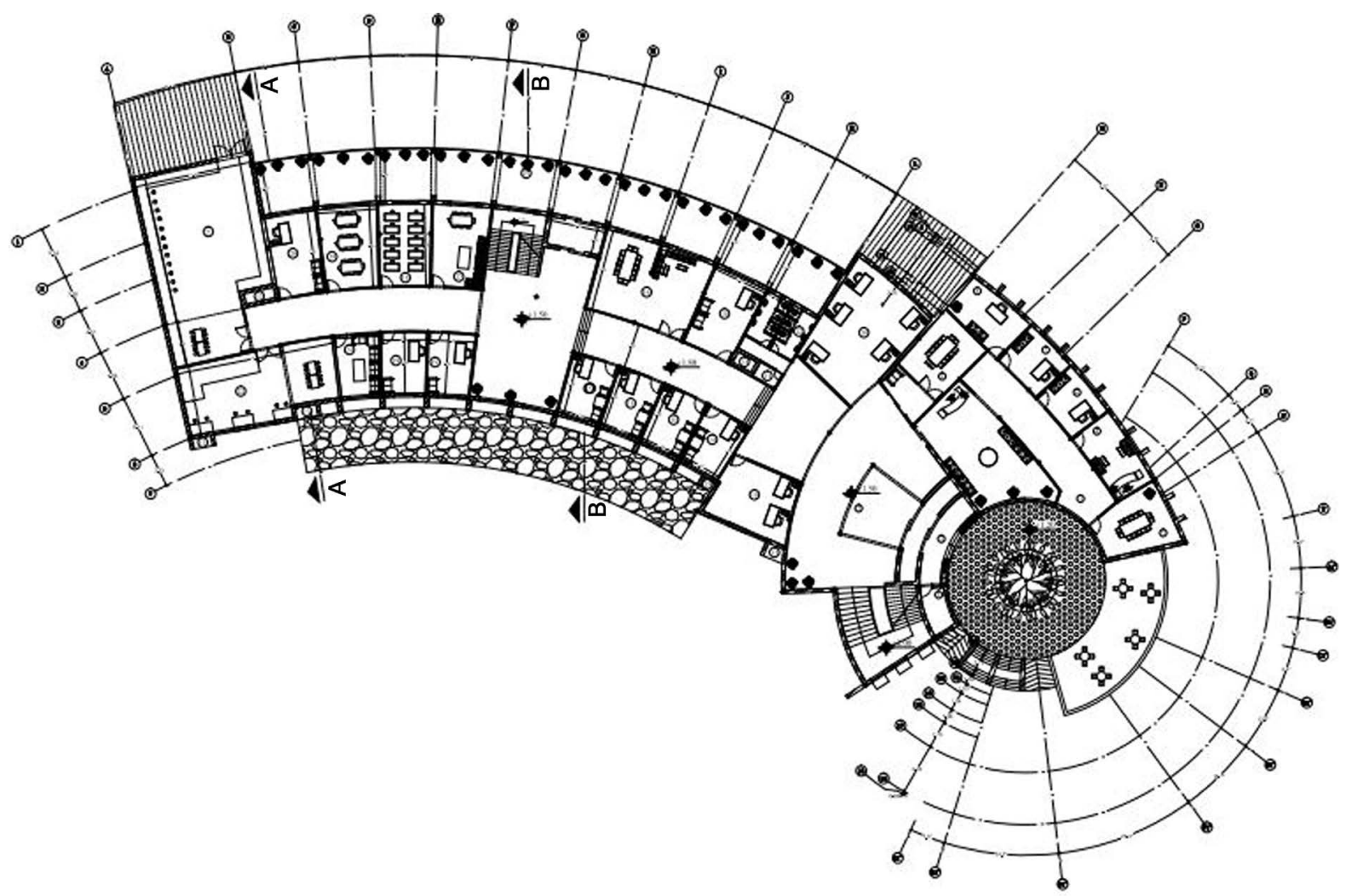

Figure 2. Ground floor plan (Authors, 2016).

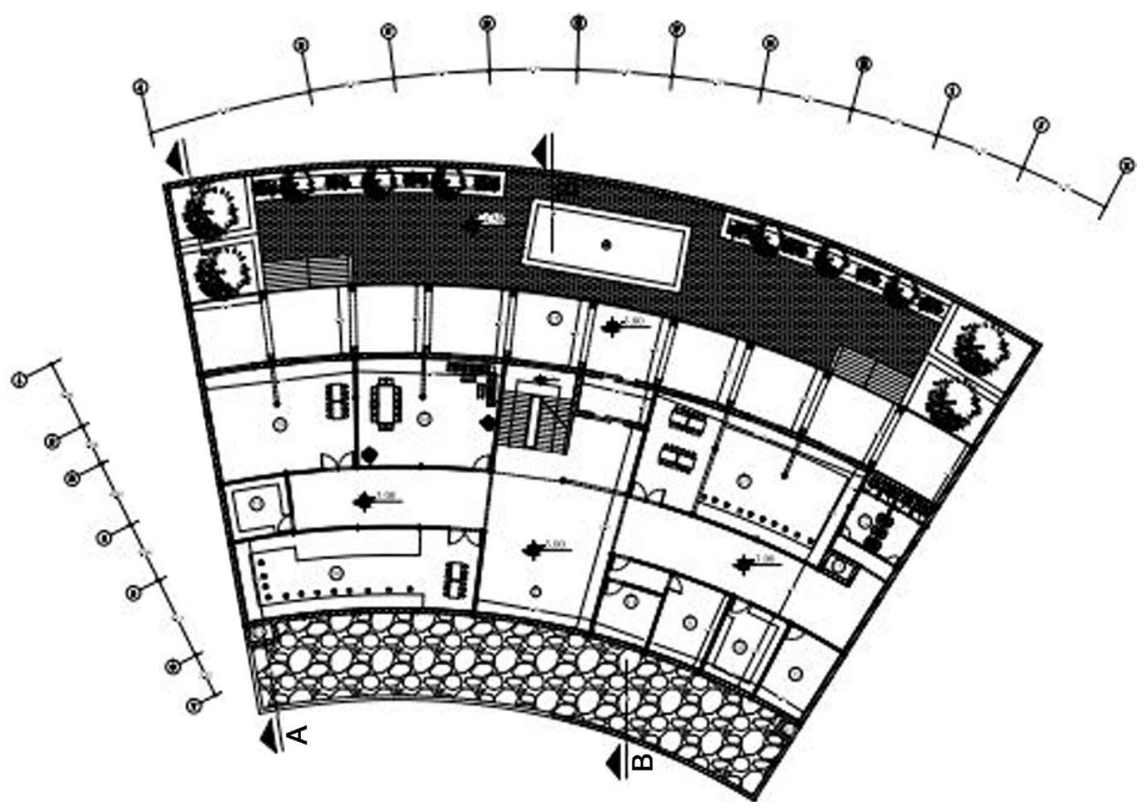

Figure 3. Underground plan (Authors, 2016). 


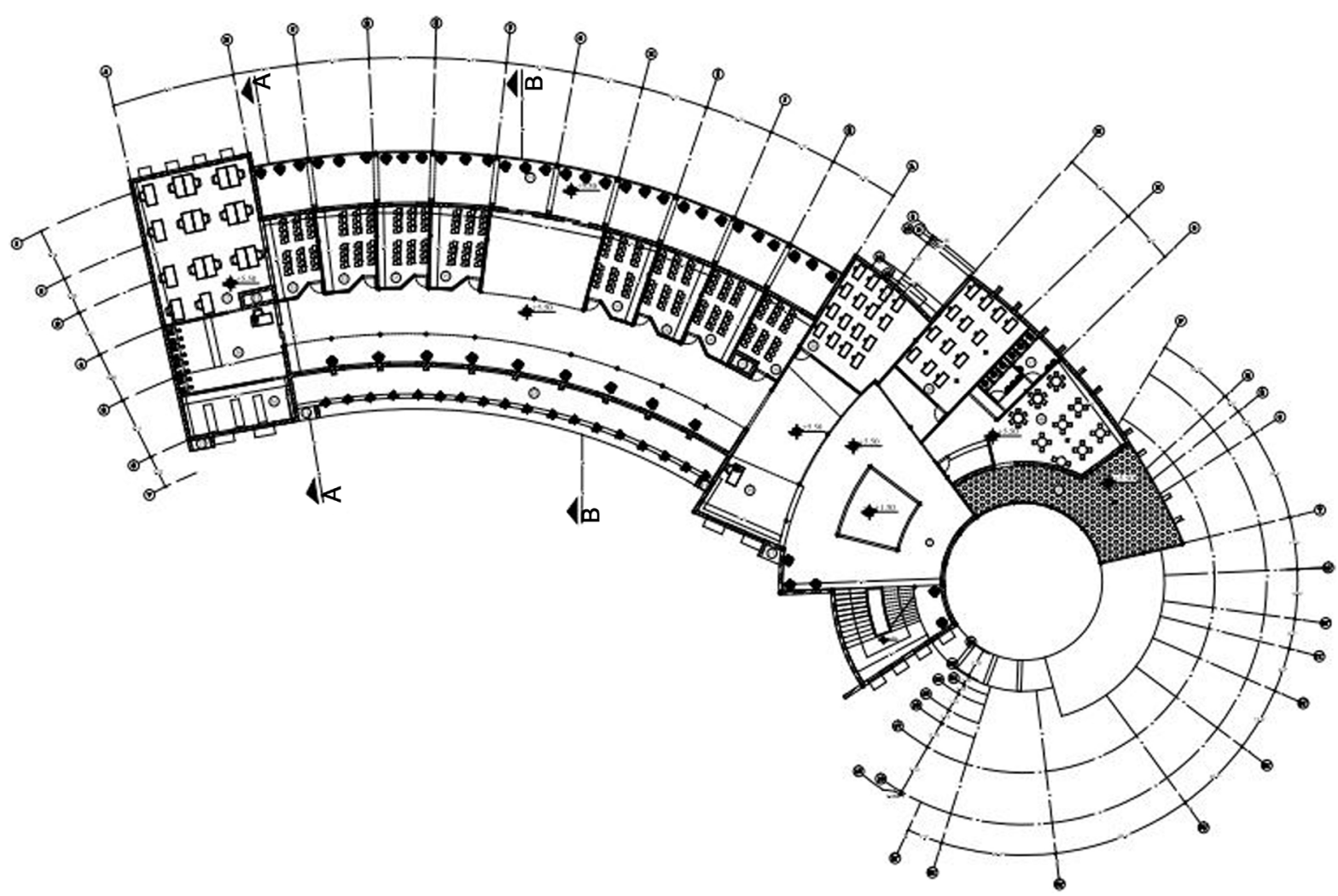

Figure 4. First floor plan (Authors, 2016).

the two types of materials and comparing their thermal behavior in the loads exerted on the building is examined.

Figure 5 indicates load changes from different sources in the summer project situations for building type 1 materials. As can be seen in Figure, Solar Gain Exterior Windows graph changes based on the sun angle during the day. On the walls, ceilings and floors heat transfer pattern is based on the thermal mass used on them. (Is stated in the description of the image.) Also the graph of load values for general lighting, computer \& equipment and occupancy is a function of timing and almost constant, and the values related to the External Vent and External Infiltration based on rising temperatures varies during the day and attendance. Figure 6 also is related to the analysis of the summer condition for type 2 materials, and as one can see except reduction in the load related to the walls, it is not observed any change in other applied loads.

Figure 7 indicates the inside and outside temperatures in the winter project (the coldest day of the year) as well as heating loads applied to different parts of the building, by the materials of Type 1 . As it can be seen, the heating load of the whole building is in $245 \mathrm{~kW}$, maximum of which is $-99.60 \mathrm{~kW}$ is related to heat transfer through the walls.

By analysis the materials and View values shown in the Figure 8, it is visible that heat loading of whole building is $180 / 30 \mathrm{~kW}$ which the reduction respect to type 1 materials is related to heat transfer rate through the walls that given the rate of intermediate thermal insulation $-32 / 29 \mathrm{~kW}$ has been obtained.

However in this part to prove the effect of thermal mass in warm and dry climate in Yazd, the difference of day and night temperature is large, image of cooling load changes (from various sources of heat production) has been investigated on a week of the year when the temperature in day is higher and in the night is lower than the comfort temperature (5th-11th October).

Figure 9 shows the load changes from different sources, and as can be seen, from 12:00 pm to 5:00 am due to the heated walls, the wall is dissipating the heating to the building that in this timeframe the outside air temperature is lower than the comfort temperature, and the heat of walls which is given back inside (and outside) environment due to the absorption of heat of the day and storage in wall layers, and its disposal happens at night. So, the walls after being isothermal with environment, they begin to absorb heat from inside of the building. As can 
M. Habibi Anbouhi et al.

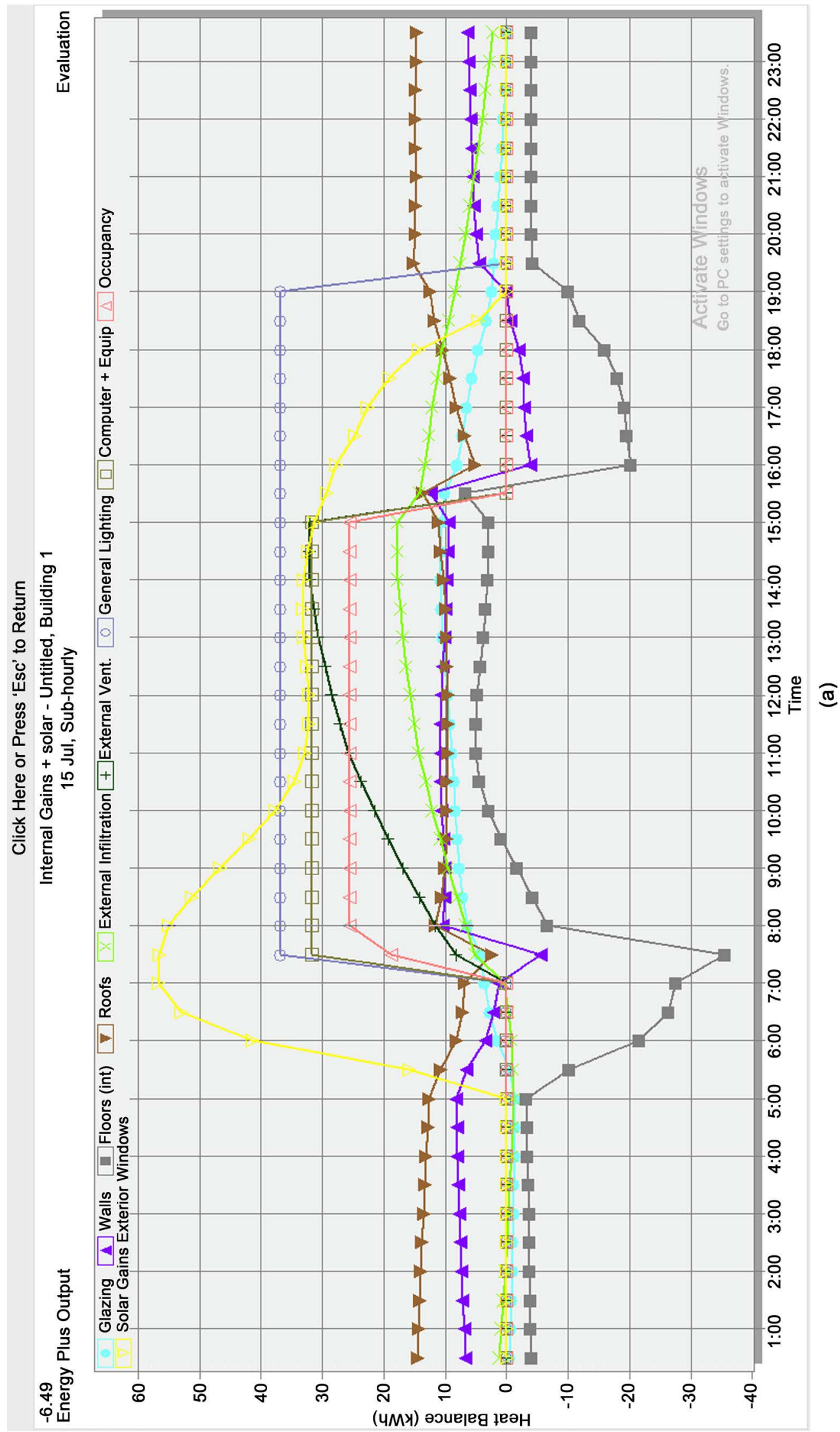




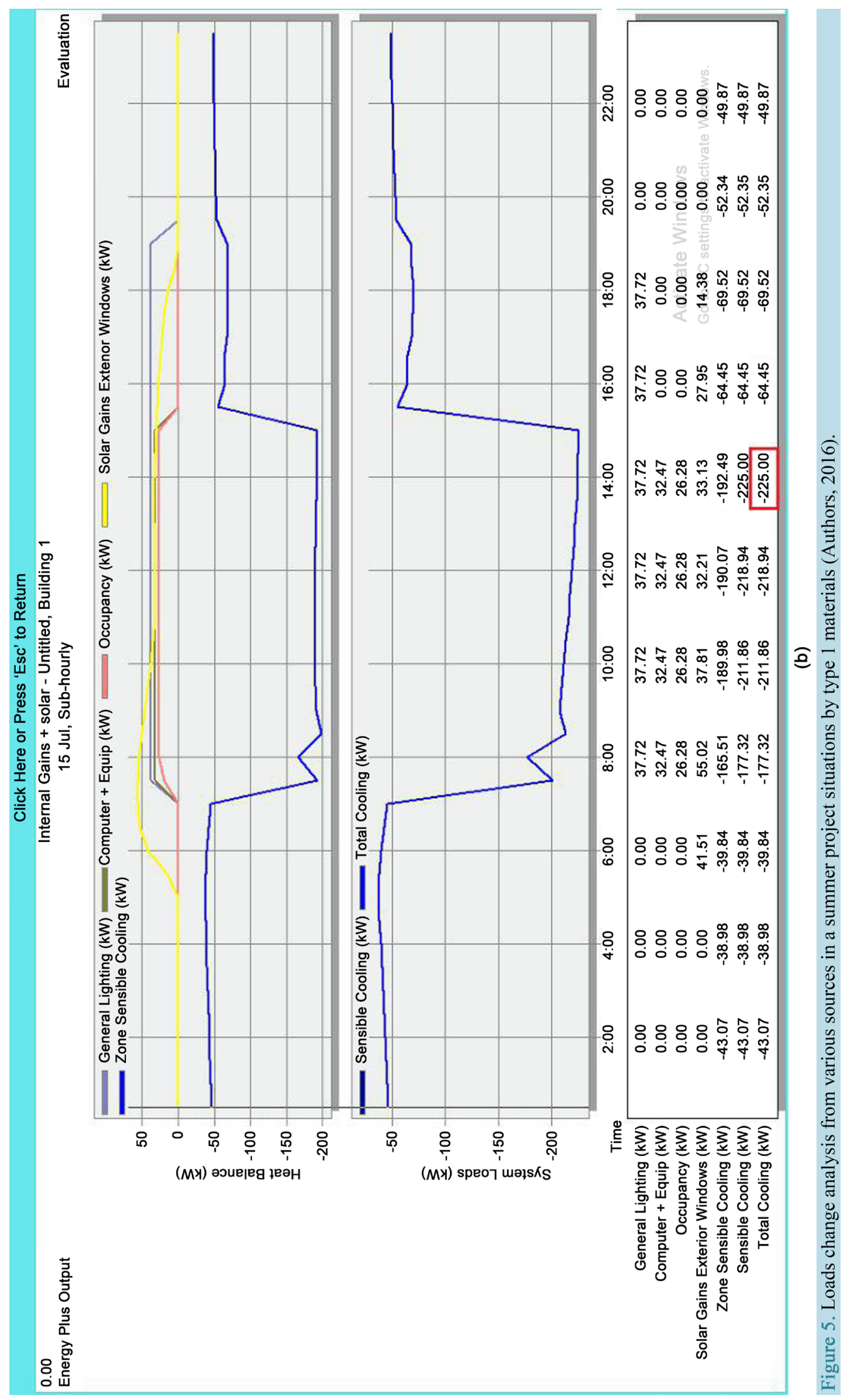


M. Habibi Anbouhi et al.

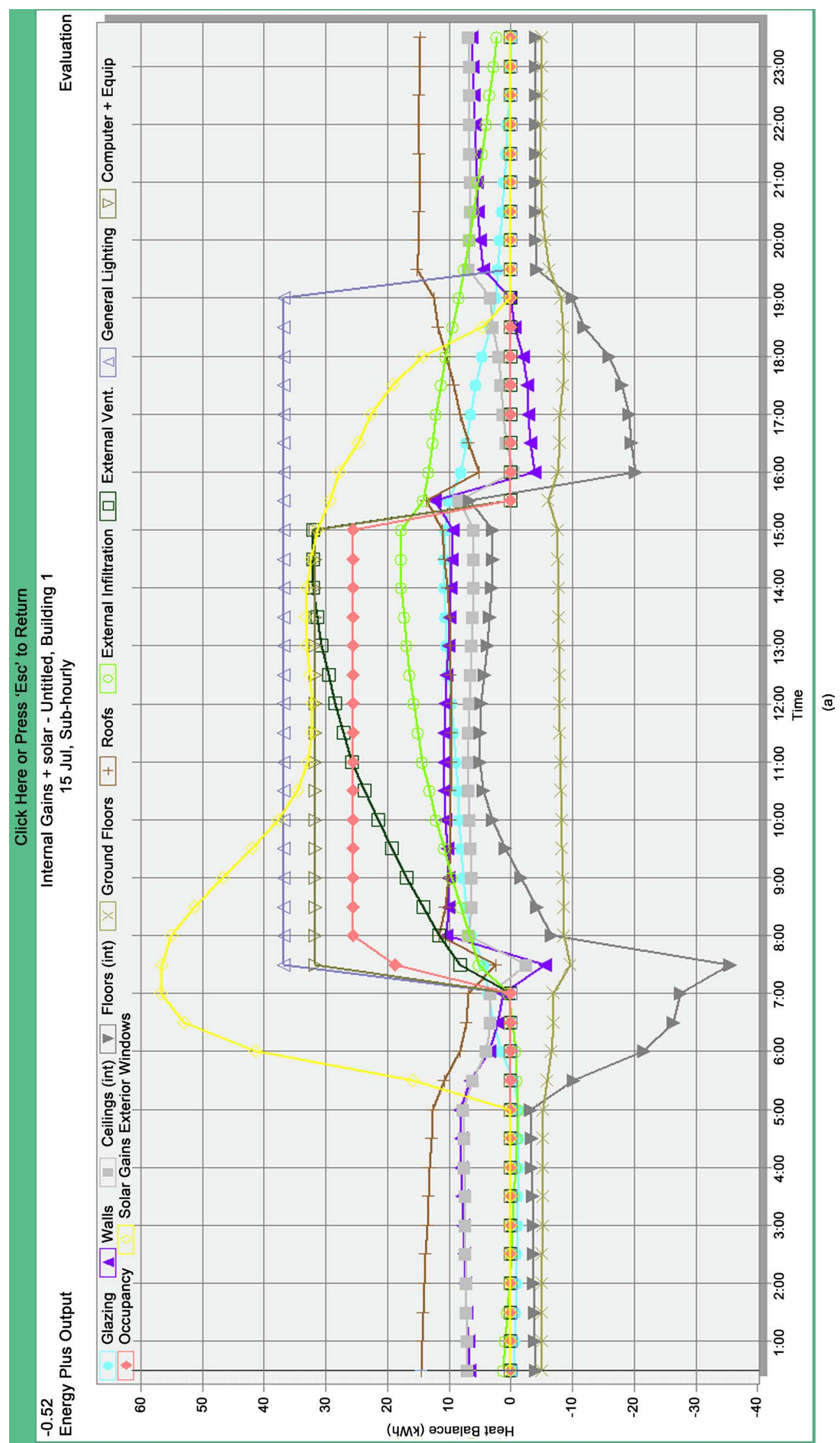




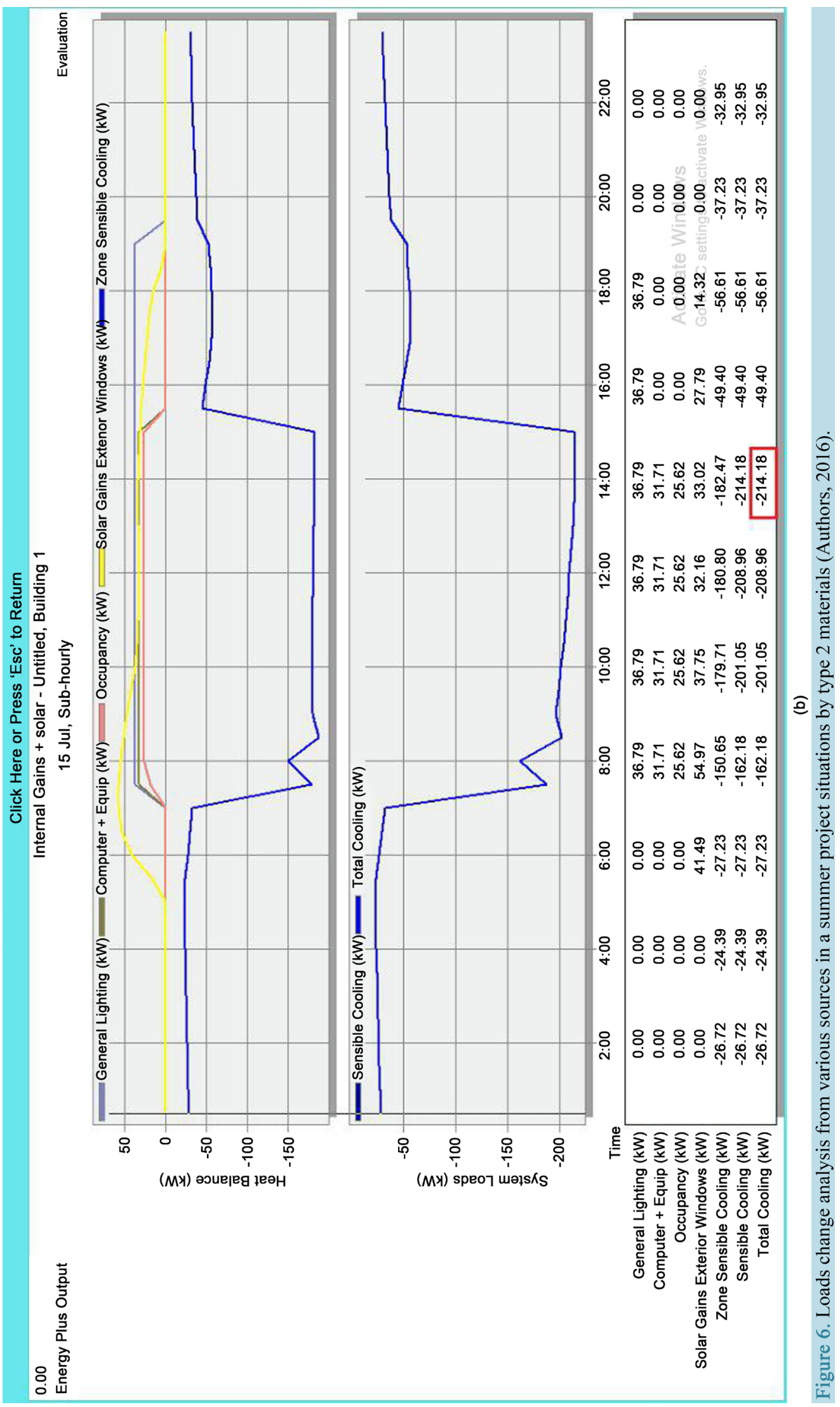




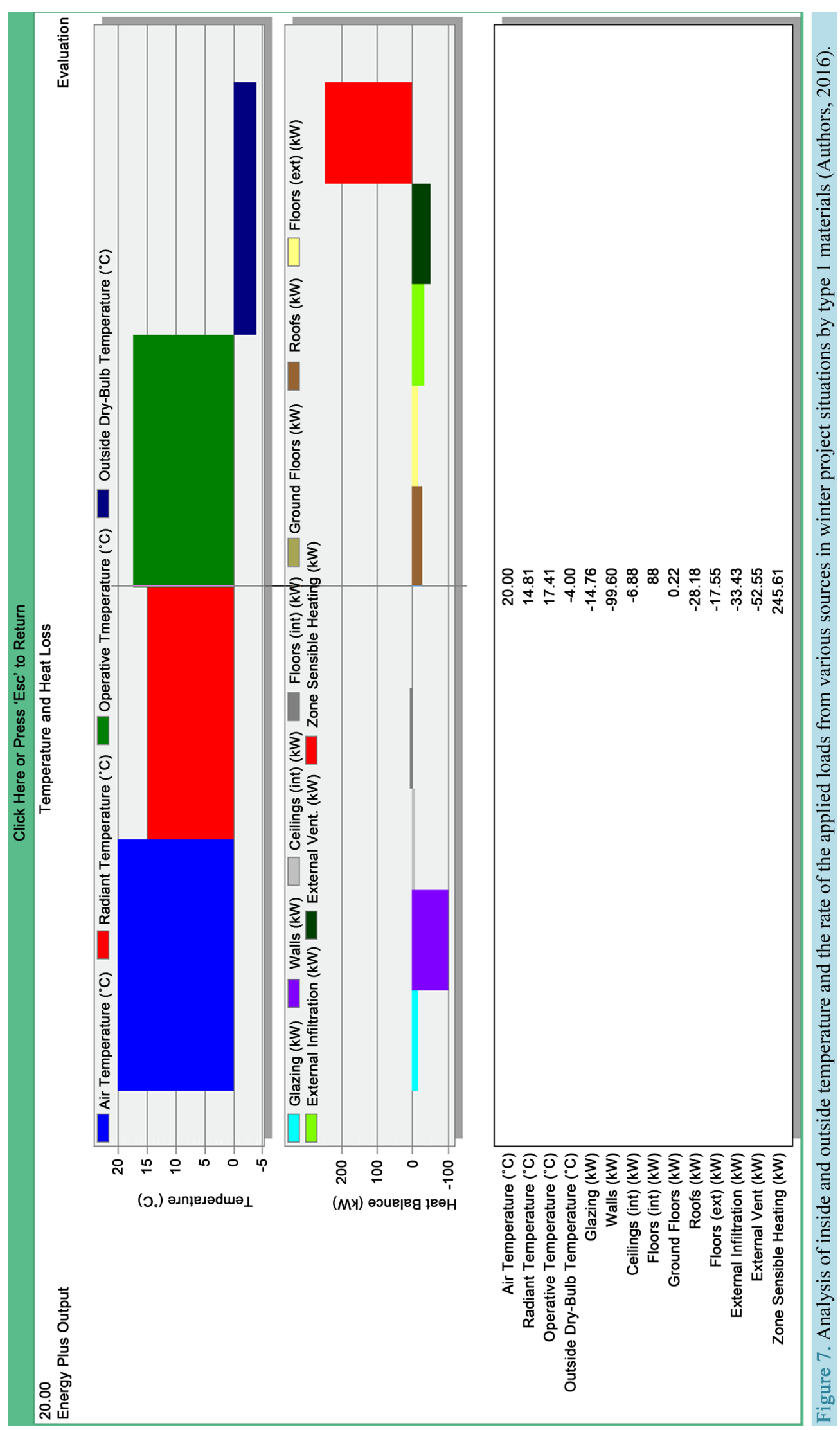




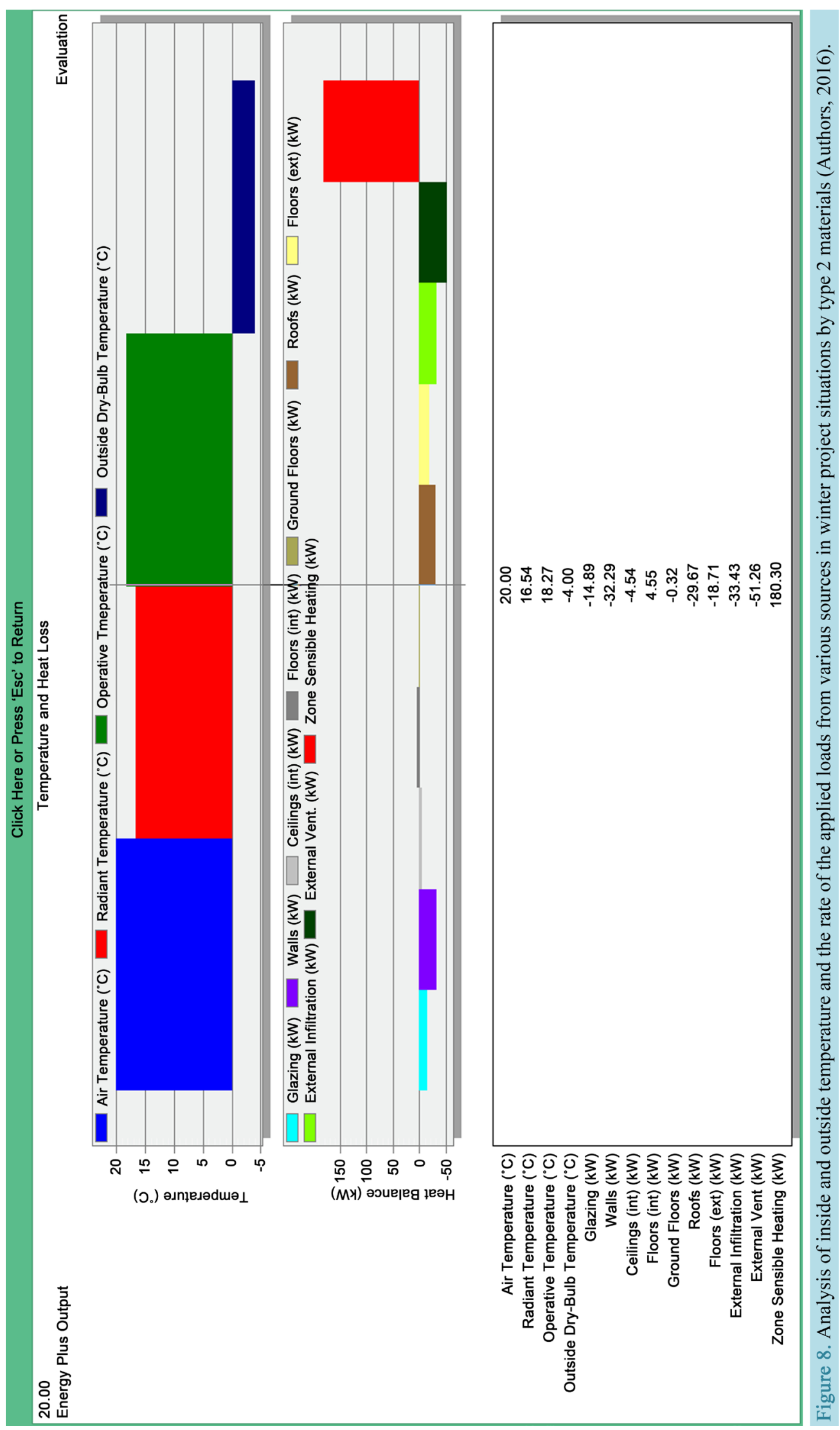


M. Habibi Anbouhi et al.

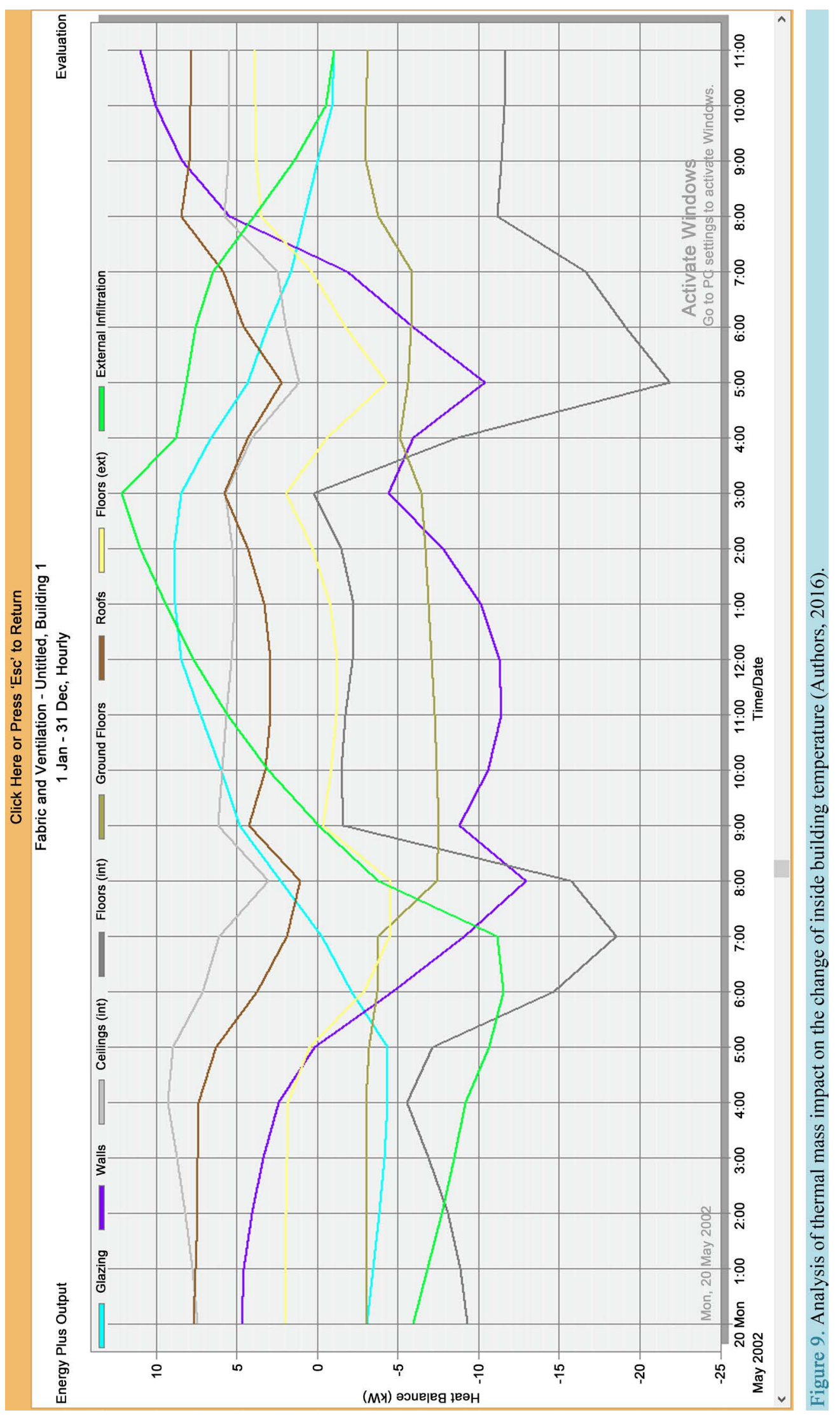


be seen, from 5:00 am to 7:00 pm blue graph of wall is below the zero line and indicates the heat absorption but because of the sunshine the outer layers of the wall is began warming up from the early hours of morning, however, since the thermal mass of walls is high, double layer with high thickness has been used. The rise in temperature of the wall layers takes time, the outer layers are warming up and the inner layers of the walls are cool and the heat of internal environment would have been tapped, this process will continue until the negative temperature gradient reaches to the inner layers, and increases the temperature of the inner layers of wall. In Figure 9 we see that it occurs at 7:00 pm, and wall transfer heat has become positive, and is dissipating the heat into the environment.

Re-cooling of the wall occurs when the outside temperature has been cooler than the temperature of the wall. In this case, the wall dissipates the heat both to inside and outside, and until it has not become isothermal with the environment the trend continues. After that the inside layers become isothermal with internal air, and the outside layers become isothermal with external air (and with regard to outside air when it is cooler than the indoor air), positive temperature gradient from outside to inside is happened which will led to the absorption of heat inside the building by the wall (similar to 5:00 yesterday morning which was explained).

After proving the effectiveness of the thermal mass of the building materials used in adjusting the temperature and contributing to cooling (and even heating) system at this stage, by comparing the applied loads on the building materials in both two analyzed types, the load imposed on active system design as well as the initial cost saving of construction has been calculated and shown in Table 3. As can be seen, using type 2 materials in the cooling load of $4.8 \%$ and in heat load reduction of $26.5 \%$ has been obtained which can be considered less burden on active system of design, which causes initial cost saving of the building.

Since the reduction in annual consumption of energy needed to supply heating and cooling may follow a different pattern, therefore in respect to estimate the annual energy consumption in cooling, heating has been considered separately. And the obtained results in Figure 10, Figure 11 represents the total amount of the heat (cooling load) into the building of different elements of heat production. As one can see except the walls, the load of other elements has no significant change.

Figure 12 and Figure 13 also represents the loss of heat energy from different parts of the building that comparing the two tables we conclude that the waste heat energy from the walls of the building with type 2 materials is far less than the type 1 materials.

According to the above and as shown in Table 4 in the calculation of the of type 2 materials for saving annual energy consumption of buildings by as much as $2.4 \%$ in supply cooling and $62.9 \%$ in supply heating respect to type 1 materials has decreased, and this means that the current cost of the building saving also can be achieved.

\section{Conclusions}

In this paper, to analyze the thermal behavior of materials in the building the Design Builder software has been utilized which is one of the tools used in building information modelling (BIM) technology. With the help of this software, energy consumption in the hottest and coldest days of the year as well as the annual energy consumption of buildings has been calculated and it became clear that using Type 2 materials, namely applying thermal mass and thermal insulation simultaneously, can create useful reduction in energy consumption as well as initial and ongoing costs of the building.

As we know in order to reduce the adverse effects of construction industry on the environment, investigating the sustainability of in the life cycle of building projects has attracted the attention of the custodians of the industry. However by increasing measures in the design and construction of industrial process, the design has replaced traditional methods and in this regard building information modelling technology is used due to the possibility of the parametric design and storage of information on the lifecycle of the building; they do not have limitations of traditional system design and assist experts in using intelligent 3-D model to analyze and optimize the energy, water, light, form, orientation and other various scenarios in order to achieve the sustainability goals.

Table 3. Comparison of the maximum heating and cooling loads exerted on the building in both types of materials (Authors, 2016).

\begin{tabular}{cccc}
\hline & $\begin{array}{c}\text { Type } \mathbf{2} \\
\text { materials }\end{array}$ & $\begin{array}{c}\text { Type 1 } \\
\text { materials }\end{array}$ & $\begin{array}{c}\text { Reduction in heating and cooling loads exerted } \\
\text { on the building in Type 1 materials }\end{array}$ \\
\hline Cooling Louds (kW) & 225 & 214.18 & $4.8 \%$ \\
Heating Louds (kW) & 245.61 & 180.30 & $26.5 \%$ \\
\hline
\end{tabular}



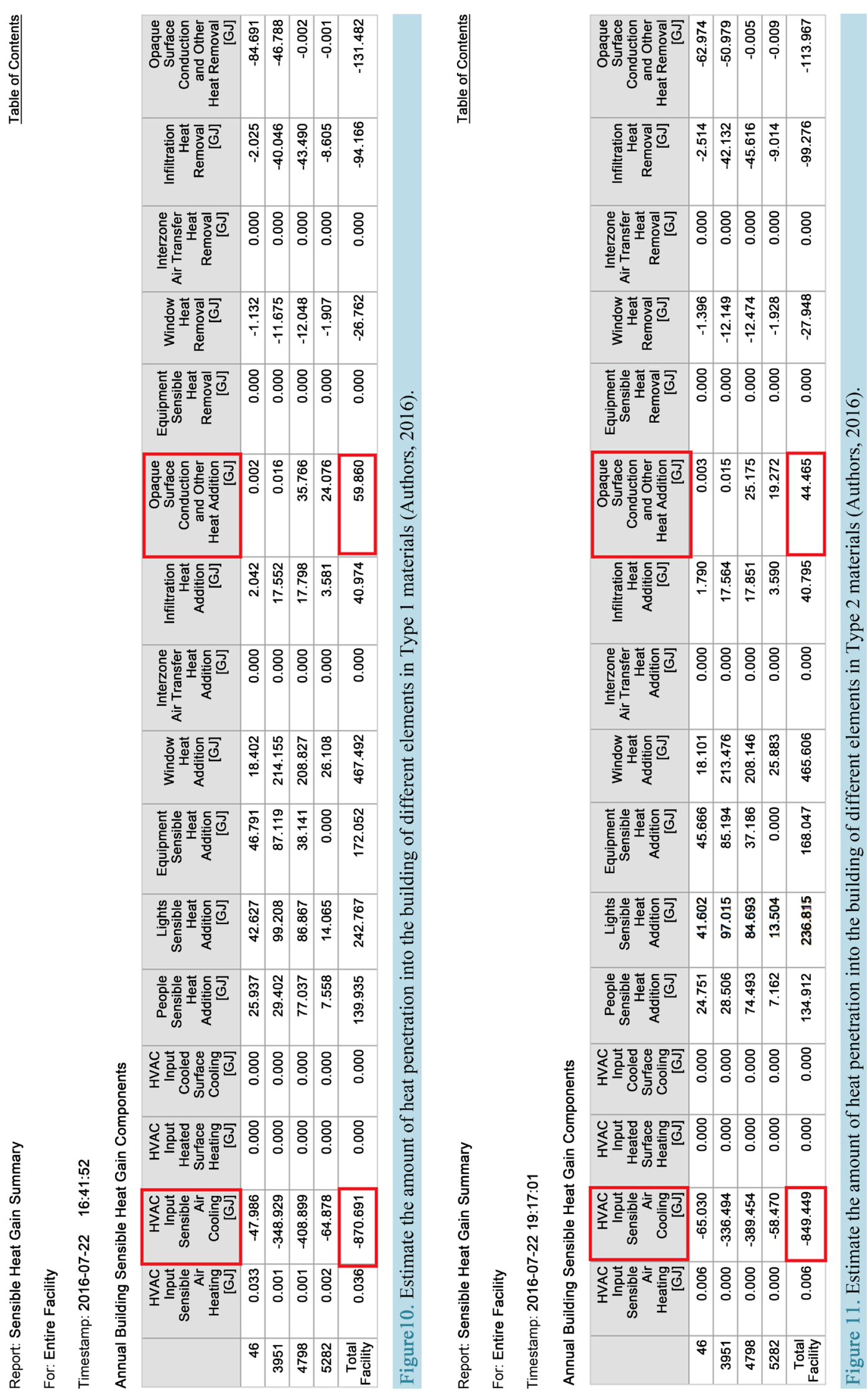


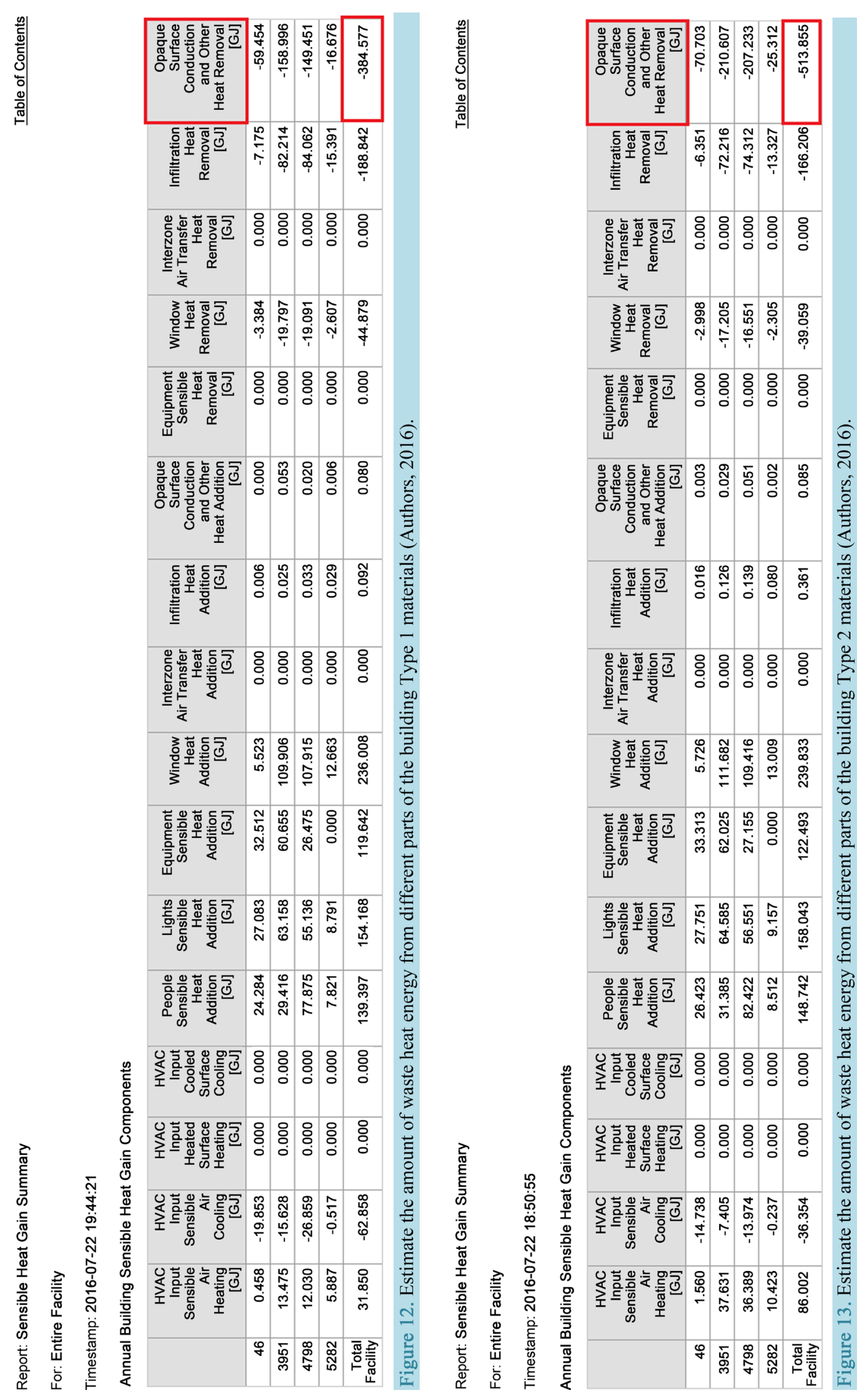


Table 4. Comparison of annual savings in energy consumption between the two types of materials (Authors, 2016).

\begin{tabular}{lccc}
\hline & Material Type 1 & Material Type 2 & Annual Energy Saving in Material Type 2 \\
\hline Cooling (GJ) & 870.691 & 849.449 & $2.4 \%$ \\
Heating (GJ) & 86.001 & 31.850 & $62.9 \%$ \\
\hline
\end{tabular}

Another factor that can contribute to reducing energy consumption in buildings using natural ventilation systems to reduce the load on cooling systems of the building related to supply cooling. It can calculate the saving in building energy consumption by building information modelling, and by utilizing the methods to be closer to sustainability goals in the construction industry.

\section{References}

[1] http://www.tavanir.org.ir

[2] Farshaidanfar, A. (2008) Modern Air Conditioning Practice Fundamental Design of Heat Exchanger. Ferdowsi University Press, Mashhad, Iran, 33-39.

[3] World Commission on Environment and Development (1987) Our Common Future. Oxford University Press, Oxford, New York.

[4] Szokolay, S.V. (2008) Introduction to Architectural Science: The Basis of Sustainable Design, Architectural Press, Oxford

[5] Zimmermann, M., Althaus, H.J. and Haas, A. (2005) Benchmarks for Sustainable Construction: A Contribution to Develop a Standard. Energy and Buildings, 37, 1147. http://dx.doi.org/10.1016/j.enbuild.2005.06.017

[6] Mahmoudi, M. (2012) Housing Development in Agreement with Sustainable Development. University of Tehran Press, Tehran, 4.

[7] Eastman, C., Eastman, C.M., Teicholz, P. and Sacks, R. (2011) BIM Handbook: A Guide to Building Information Modeling for Owners, Managers, Designers, Engineers and Contractors. John Wiley \& Sons, Hoboken.

[8] Lechner, N. (2015) Heating, Cooling, Lighting: Sustainable Design Methods for Architects. John Wiley \& Sons, Hoboken, 23.

[9] Smith, S. (2007) Using BIM for Sustainable Design. http://www10.aeccafe.com

[10] Niewoehner, D. (2010) BIM and Life-Cycle Analysis Help Determine Value of Green Strategies. Laboratory Design, 2, 3-7.

[11] Schlueter, A. (2009) Building Information Model Based Energy/Exergy Performance Assessment in Early Design Stages. Automation in Construction, 2, 153-163. http://dx.doi.org/10.1016/j.autcon.2008.07.003

[12] Stumpf, A., Kim, H. and Jenicek, E. (2009) Early Design Energy Analysis Using BIMS (Building Information Models). Building a Sustainable Future, Proceedings of the 2009 Construction Research Congress, Seattle, Washington, 44. http://dx.doi.org/10.1061/41020(339)44

[13] Welland, R.A. (2009) The Intersection of BIM and Sustainable Design. Structure Magazine, 16-17.

[14] Krygiel, E. and Bradley, N. (2008) Green BIM: Successful Sustainable Design with Building Information Modeling. Wiley Publishing, Inc., Canada, 26-27.

[15] Soltani, S. (2016) The Contributions of Building Information Modelling to Sustainable Construction. World Journal of Engineering and Technology (WJET), 4, 193-199. http://dx.doi.org/10.4236/wjet.2016.42018

[16] Wong, K.D. and Fan, Q. (2013) Building Information Modelling (BIM) for Sustainable Building Design. Facilities, 31, 138-157.

[17] http://www.designbuilder.co.uk

[18] Watson, D. and Labs, K. (1983) Climate Design: Energy Efficient Building Principles and Practices. McGraw-Hill, New York, 37.

[19] Givoni, B. (1998) Climate Considerations in Building and Urban Design. Van Nostrand Reinhold, the USA.

[20] De Saulles, T. (2011) Thermal Mass Explained. TCC (The Concrete Center), Surrey.

[21] Department of Climate Change and Energy Efficiency (DCCEE) (2010) Your Home: Technical Manual. 4th Edition, Commonwealth of Australia. www.yourhome.gov.au

[22] Gregory, K., Moghtaderi, B. and Sugo, H. (2008) Effect of Thermal Mass on the Thermal Performance of Various Australian Residential Constructions Systems. Energy and Buildings, 40, 459-465.

http://dx.doi.org/10.1016/j.enbuild.2007.04.001 
[23] Balaras, C.A. (1996) The Role of Thermal Mass on the Cooling Load of Buildings. An Overview of Computational Methods. Energy and Buildings, 24, 1-10. http://dx.doi.org/10.1016/0378-7788(95)00956-6

[24] McMullan, R. (2012) Environmental Science in Building. 7th Edition, Palgrave Macmillan, New York.

[25] http://www.moe.gov.ir

[26] ASHRAE Standard 55 (2010) Thermal Environmental Conditions for Human Occupancy. ASHRAE, Atlanta.

[27] Fishman, D.S. and Pimbert, S.L. (1979) Survey of Subjective Responses to the Thermal Environment in Offices Indoor Climate. Danish Building Research Institute Copenhagen, Denmark.

[28] Sadegiravesh, M. and Tabatabi, M. (2008) Determining the Thermal Comfort Rang in the Hot Arid Climate. HoviateShahr, 9, 39-46.

\section{Submit or recommend next manuscript to SCIRP and we will provide best service for you:}

Accepting pre-submission inquiries through Email, Facebook, LinkedIn, Twitter, etc.

A wide selection of journals (inclusive of 9 subjects, more than 200 journals)

Providing 24-hour high-quality service

User-friendly online submission system

Fair and swift peer-review system

Efficient typesetting and proofreading procedure

Display of the result of downloads and visits, as well as the number of cited articles

Maximum dissemination of your research work

Submit your manuscript at: http://papersubmission.scirp.org/ 